\title{
An Unusual Case of Gilbert Syndrome -A Case Report
}

\author{
Authors \\ Harharpreet Kaur $^{1 *}$, Kiranjit Kaur ${ }^{2}$, Kiran Kumar Singal ${ }^{3}$, Surinder Kumar \\ ${ }^{1}$ Professor, Department of Medicine, MM Medical College, Kumarhatti, Solan \\ ${ }^{2}$ Professor Department of Biochemistry, MM Medical College, Kumarhatti, Solan \\ ${ }^{3}$ Professor, Department of Medicine, MM Medical College, Kumarhatti, Solan \\ ${ }^{4}$ Assistant Professor, Department of Medicine, MM Medical College, Kumarhatti, Solan \\ *Corresponding Author \\ Dr Harharpreet Kaur
}

Professor Medicine, MM Medical College, Kumarhatti, Distt. Solan, Himachal Pradesh, India Ph 9872777800, Email: dr.harharpreet@ gmail.com

\begin{abstract}
Gilbert syndrome is caused by a mutation and deficiency of the conjugating liver enzyme uridine diphosphoglucoronate-glucoronosyltransferase. It is characterized by episodes of mild unconjugated hyperbilirubinemia which is usually less than $3 \mathrm{mg} / \mathrm{dl}$.It may pose a diagnostic problem if the level of bilirubin is high as in our case where it was persistently more than $6 \mathrm{mg} / \mathrm{dl}$. However the diagnosis can be established by ruling out other causes of unconjugated hyperbilirubinemia such as haemolysis and vit B12 deficiency. Liver enzymes and ultrasound of abdomen are normal. The patient was typically asymptomatic inspite of deep jaundice. The general practioners need to keep this uncommon cause of jaundice in mind to avoid unnecessary panic and medication as this condition is basically benign and needs only reassurance.
\end{abstract}

Keywords: Gilbert syndrome; unconjugated hyperbilirubinemia.

\section{Introduction}

Gilbert syndrome was first described by Augustin Gilbert and Pierre Lereboullet in $1901{ }^{1}$. It is a benign, familial condition which manifests itself near adolescence. It is diagnosed by a history of mild intermittent asymptomatic jaundice due to unconjugated hyperbilirubinemia. The impaired bilirubin conjugation is due to decreased levels of the uridine diphosphateglucuronosyltransferase enzyme in the liver. Bilirubin UGT activity is about $30 \%$ to $70 \%$ of normal. This is the result of a mutation in the UGT1A1 gene. ${ }^{2}$ There is evidence for a defect in the hepatic uptake of bilirubin as well. The diagnosis is made by the demonstration of a raised bilirubin level that is predominantly unconjugated. The liver enzymes are normal and there is no evidence of haemolysis. The hyperbilirubinemiais by definition $<6 \mathrm{mg} / \mathrm{dl}$ most patients exhibiting levels of $3 \mathrm{mg} / \mathrm{dl} .^{3}$ It may be normal with daily and seasonal variations. Episodes of jaundice are often precipitated by stress, fasting, vigorous exercise, intercurrent illness or dehydration and resolve spontaneously. 
The prevalence of Gilbert syndrome is $3-7 \%$ of the population. ${ }^{4}$ The course is benign but the diagnosis may be challenging when it presents with severe jaundice.

\section{Case Report}

Our patient was a 26 year old married woman mother of two children who presented with a history of jaundice which had been deepening progressively during the last 3 weeks. She had suffered from a brief episode of fever a month ago. She was active and cheerful with no history of fatigue or loss of appetite. Urine and stool color was normal. There was no hepatomegaly. Investigation reports were as follows-Total Bilirubin $14 \mathrm{mg} / \mathrm{dl}$, bilirubin direct- $0.38 \mathrm{mg} / \mathrm{dl}$, SGOT-29U/L, SGPT-47U/L, Alkaline phosphatase $-56 \mathrm{U} / \mathrm{L}$, Albumin $4.5 \mathrm{gm} / \mathrm{dl}$, Total protein $7.57 \mathrm{gm} / \mathrm{dl}$. Bile salt, bile pigment and urobilinogen were absent from urine. Common viral markers were negative. Ultrasound of abdomen was normal. $\mathrm{Hb}$ was $12.6 \mathrm{gm} / \mathrm{dl}$, TLC$6000 \mathrm{~mm}^{3}$, PCV $36.5 \%$, 'MCH-29.5pg, MCV 83.4FL and MCHC was $34.5 \%$ all within normal range. Peripheral Blood film did not show any evidence of haemolysis. Reticulocyte count, Vit B12 and folate levels were normal. Symptomatic and supportive therapy was given. After 4 days the bilirubin levels had decreased to $12 \mathrm{mg} / \mathrm{dl}$, direct being $0.26 \mathrm{mg} / \mathrm{dl}$. Within 2 weeks the bilirubin levels had decreased to $8 \mathrm{mgm} / \mathrm{dl}$. (mostly unconjugated) After another month they were still between $8-10 \mathrm{mg} / \mathrm{dl}$ but the patient continued to be completely asymptomatic.

\section{Discussion}

Normal liver enzymes and a normal liver on imaging ruled out any liver disease or viral hepatitis. There was no evidence of haemolytic anemia which is characterized by unconjugated bilirubinemia which is of a milder degree and accompanied by severe anemia. Vit B12 leads only to a mild unconjugated hyperbiliribinemia. The only possibility left was that of Gilbert syndrome. On further questioning the patient admitted to a history of fluctuating jaundice for past many years ever since she was a young girl and the bilirubin levels remained from 6 to 10 $\mathrm{mg} / \mathrm{dl}$. This time it had increased to $14 \mathrm{mg} / \mathrm{dl}$ which later decreased to $8-10 \mathrm{mg} / \mathrm{dl}$. Eduardo et al reported two cases who presented with persistently high unconjugated bilirubin levels of more than $6 \mathrm{mg} / \mathrm{dl}$. They were diagnosed with Gilbert's syndrome and confirmed by genetic analyses and had some similarity with our case. It is possible that in our case the febrile illness one month ago had served as a trigger and caused the increased levels of bilirubin.

The diagnosis of Gilbert syndrome must be suspected when there is persistent jaundice and elevation of unconjugated bilirubin in the absence of other causes of indirect hyperbilirubinemia. In addition liver enzymes need to be normal. Other diagnostic tests include the increase in serum bilirubin on fasting or following intravenous nicotinic acid and the fall on taking phenobarbitone which induces hepatic conjugating enzymes ${ }^{4}$ Genetic testing can be done.But these are not mandatory for diagnosis.

\section{Conclusion}

Our case report concurs with a previous report where $\mathrm{S}$ bilirubin levels may be higher than normally described. The general practioners need to keep this uncommon cause of jaundice in mind to avoid unnecessary panic and medication as this condition is generally benign and non progressive and the patient needs to be reassured.

\section{References}

1. Watson KJR, Gollan JL. Gilbert's syndrome. Clin Gastroenterol 1989;3: 337.

2. Koiwai O, Nishizawa M, Hasada K, et al. Gilbert's syndrome is caused by a heterozygous missense mutation in the gene for bilirubin UDPglucuronosyltransferase. Human molecular genetics 1995;4:1183-6.

3. Felsher BF, Rickard D, Redeker AG. The reciprocal relation between caloric intake 
and the degree of hyperbilirubinemia in Gilbert's syndrome. N Engl J Med 1970;283:170-2. DOI: 10.1056/NEJM197007232830403.

4. Sherlock S, Dooley J. Jaundice. In: Diseases of the liver and biliary system, 11th ed. London: Blackwell; 2002: p. 2147.

5. Eduardo Flores et al Unusual presentation of Gilbert disease with high levels of unconjugated bilirubin. Report of two cases, Rev. esp. enferm. Madrid abr. 2016. dig. vol.108 no.4 